\title{
Structural Changes That Generate Competitive Ability to the Metal Working Industry
}

\author{
Dionise Magna Juchem \\ Federal Institute of Rio Grande do Sul, Restinga, Brazil \\ Claudio Edilberto Hofler, Edgardo Alfredo Herrera Céspedes \\ Federal Institute Farroupilha, Santa Rosa, Brazil \\ Fábio Augusto Marin \\ Federal Institute of Rio Grande do Sul, Veranópolis, Brazil
}

\begin{abstract}
This article presents the results of a study conducted in a Metallurgical industry located in the town of Santa Rosa-Rio Grande do Sul State, Brazil. Its central goal was to obtain a better understanding of the structural changes in the organization and identify its working practices through both case and bibliographic studies, taking into consideration the technological advances and the new management being implemented in the company, due to its acquisition by a multinational company. The proposal of a new organizational structure which has brought inevitable changes to the organizations but the structure needs to be well defined to lead to the company under study and its employees the best way, through continuous improvement and competitive entrepreneurship. The results obtained enable a better understanding of the history and nature of changes in the organization, considering it as a living and changing system.
\end{abstract}

Keywords: management, leadership, motivation, management teams

\section{Introduction}

The contemporary world is undergoing changes, the digital revolution, globalization of markets, management innovation, and an economy based on the value of information and innovation. These changes mean that companies take an adaptation strategy which gives them competitive advantage. However, these changes in the business world are generating new opportunities, new products, new management, and new challenges to entrepreneurs.

In this context of new possibilities, the challenges related to people management have changed; there are new challenges, as Borges, Lima, and Vilela (2004) highlighted, versatility: the multi-functionality of the

Dionise Magna Juchem, Ph.D. in Management and Direction of Companies, Department of Business and Management, Federal Institute Rio Grande do Sul, Restinga, Brazil.

Claudio Edilberto Hofler, Ph.D. in Management, Department of Business and Management, Federal Institute Farroupilha, Santa Rosa, Brazil.

Edgardo Alfredo Herrera Céspedes, MBA in Engineering and Materials Technology, Department of Mechanical, Federal Institute Farroupilha, Santa Rosa, Brazil.

Fábio Augusto Marin, MBA in Management and Organization, Department of Management and Organization, Federal Institute of Rio Grande do Sul, Veranópolis, Brazil.

Correspondence concerning this article should be addressed to Dionise Magna Juchem, Rua Dois de Novembro, 49/303 Bairro Tarumã, CEP 94415-660, Viamão, Rio Grande do Sul, Brazil. E-mail: dionisejuchem@gmail.com. 
worker, the need of better qualified workers, and willingness to participate, learn, and cooperate. However, these changes are accompanied by withdrawal or reduction of the employees' support system, such as stability, career plans, benefits, and assistance system, among other factors. Changes is occurring where organizations need to adapt to the new working rules, leaving aside the thought that competitive stability come when you are winning the game. Therefore, companies and managers must always remain competitive. This study aims to engage and examine how organizations are adapting to this new reality, based on four topics: organizational structure, organizational strategies, organizational marketing, and people management for the development of their competitive business advantage.

\section{Theoretical Framework}

\section{Organizational Structure}

The current world is going through a period of great social, political, and economic transformations. It's what may be called globalization. According to Sacomano and Escrivão (2000), seeking comprehension and understanding the changes in organizations are extremely exciting and no simple task. Each organization has its own "dialect" to manifest how the tasks are carried out within the setoff information and relationships that make up the organizational structure. It resembles a kaleidoscope, always changing to the eye, but extremely faithful to its geometry, while not changing the instrument.

According to Feurschutter (1997), the concept of organization requires the interaction among individuals, through social relationships that develop based on the principles and objectives defined in the organizational structure.

It may be noted that each organization has a defined structure, but the constant changes in the world can question managers about what structure would be best for the organization in the fast moving world that companies are inserted. The organizational structure is the company in all its sectors, it is where all the organization productive gain takes place, activities are distributed, and where it is usually represented by a hierarchically distributed organization chart.

In the view of Souza and Aguiar (2011), at the time of Fayol, the organizational chart already had the basic functions of: (a) staff (recruitment, organization, and operation), (b) exploitation and manufacturing, (c) maintenance and construction, (d) sales and purchases, and (e) accounting, finance, and diverse. The concepts developed by Fayol, demonstrate the outset, in the early 20th century, of common management practices used in 21 st century organizations, such as the decentralized structure, continuing education programs and succession, the use of benchmarking procedures, structured planning focused on long-term, corporate governance, and strategic management.

In 1991, Allen and Meier introduced a conceptualization of three components of organizational commitment: a desire (affective commitment), a need (instrumental commitment), and an obligation (legal commitment) for an organizational management. In this context, it is through these and many other studies that companies are changing their management, making it more decentralized, and using benchmarking as an important and strategic tool for improvement. Focusing their strategies in the long term and new possibilities of organizational structure, that offers an effectively collaboration to the achievement of goals.

\section{Organizational Strategies}

The concept of strategy has been widely used in the business world for some time; it contributes to the 
success of the company and is a very important concept in the routine of managers.

The globalization of business is speeding up changes in terms of how the production of goods and services is being planned and implemented to meet an increasingly demanding and attentive to social change consumer.

One of the main characteristics of the new economy is the transition from individual to collective efficiency. Competitiveness is and will increasingly be related to the performance of inter-organizational networks rather than individual companies.

Discussions about the factors that determine the competitiveness of companies have been enriched in recent years with new approaches. The main point that companies must analyze are their products and services, identifying their strengths and their weaknesses, so that trends and opportunities can be analyzed.

According to A. C. C. Fleury and M. T. L. Fleury (2003), operational excellence strategy is applied by companies competing in markets where the price/quality ratio is the major determinant of the competitiveness of products or services and the innovation in products.

Companies that compete with and product innovation strategy are continually investing to create concepts of radically new products and/or services to defined customers and market segments. When they are customers orientated, they adopt the customers-oriented strategy, focus on the needs of specific customer needs, and seek to specialize in product development, systems, and solutions that meet current and future demands.

The operational strategy links quality to price, that is, the profit is coupled to the product/service and the production of these. The innovation strategy is linked to new things to market and innovation to prospective markets. When client oriented, this kind of strategy seeks to satisfy customer needs with new products and services.

Consequently, these strategies are part of the strategic planning that is also a long-term strategy that helps companies to focus on short and long term. In fact, the strategic management is established as an administrative methodology used to establish the best strategic direction for the organization, aligned to its environment.

\section{Organizational Marketing}

In the business world, marketing is very important for the success of the organization, because it views the relationship between the company's products and services and its customers, becoming a competitive advantage in business. According to R. P. Brito and L. A. L. Brito (2012), it establishes the creation of greater value than the direct competitors, it is also the first competitive advantage, comprising the scope between the willingness to pay and the opportunity cost of the company.

Marketing is the process currently used to determine which products or services may be of interest to consumers, as well as the strategies to be used in sales, communications, and business development. The purpose of marketing is to create value and customer satisfaction, managing profitable relationships for both parties. The activities of a marketing manager cover a very large range of activities, from market research, strategy definition, advertising, sales, and after-sales service.

According to Keller and Kotler (2009), business success often depends on the ability of marketing, finance, operations, accounting, and other business functions that do not make sense, if there is not a sufficient demand for products and services for the company to obtain profit.

It is undeniable that marketing is a constituent part of the organizational context and is an advantage that internally and externally covers the organization, focusing on all sectors of products and services and creating value and customer satisfaction. 


\section{People Management}

Managing people can be the most difficult goal for managers, because each person has different characteristics. People management is essential to keep the company in balance and ensure the rights and duties of each individual.

According to Jabbour and Santos (2007), the management of human resources is the organizational function that deals with people. The role of human resources and their management activities aims to use people to achieve the business objectives. The human resources management is in charge of personnel management within organizations, also introducing the importance of environmental laws and employees life quality. It is argued that caring for people in their workplace and the environment should be a policy of the whole; taking into account the changes occurring in the labor market, organizations need to have clear strategies, supported by a participative management.

Close links among all levels of relationship, both internal and external of the staff, through to customers and suppliers must be developed. Human resource management practices is an important ancestor of organizational culture, which in turn generates a positive relationship to organizational performance, based on a model that has been recently discussed, competence management (Al-Bahussin \& El-Garaihy, 2013).

Competence management, according to Rabechini and Carvalho (2003), comes from the Latin, competere. It originates from the decomposition of the Latin words: com, meaning together and petere, meaning effort.

Skills management has focused on training the individuals' experiences and skills that add value to the company. Many authors divide the management skills in three parameters: the individual, the team, and the company. Therefore, people are a fundamental part in the company development, it is they who, with their experience and training, add value to the work, making the organization grow, innovate, and profitable and competitive

\section{Methodology}

This study aims to identify how organizations are adapting to the new global reality: a world in constant change and technological advances.

The methodology was a descriptive and exploratory case study coupled with bibliographic basement. Data collection for this study was made through interviews, use of questionnaire, and analysis of company provided documents, with executives of a metallurgical industry located in the town of Santa Rosa, Rio Grande do Sul State, Brazil.

The first phase of the study was the choice of the company, the company was chosen, because it belongs to a promising business area in the region, the metal-mechanic sector. Some data have been raised by researchers and demonstrate the size of the agricultural machinery and equipment sector, which has registered very significant sales growth, due to the stimuli received for the modernization of agriculture through federal incentives in Brazil

The second phase interviews with managers were carried out and afterwards, the data was compiled, the results were analyzed, the company's history was described, as well as the results of the study and final considerations.

The results obtained enable a better understanding of the history and nature of changes in management and their respective forms of work organization. 


\section{Company History}

The company believes that it is people who make the difference and make a history of growth and success possible; its history began in 1960 and until August 29, 2010, it was 50 years.

In 1953, Johanness found in Não-Me-Toque/Rio Grande do Sul State, a blacksmith shop. The company, Stapelbroek Rauwers \& CIA. Ltd., was primarily engaged in the assembly and maintenance of agricultural machinery and tools imported from Europe that were beginning to arrive in the region. The need to adapt products to the regional characteristics, soil, and cultures drove the manufacture of new implements.

In 1960, agriculture enabled business to grow; the society was undone by agreement, giving rise to the Stapelbroek Rauwers \& CIA. Ltd.. Johannes and his sons started manufacturing agricultural machinery and marketed the first cultivator with wheels, steerable, and floating arms made in Brazil. It was the beginning of the company's tradition of creating solutions for farmers.

In 1978, in order to expand, structural changes are implemented in the company; that is the opening of the new industrial area.

In 1982, financial difficulties led to the open of the social capital and the transformation in S/A, bringing new partners, new ideas and capital, the main new partner was Franciscus Stapelbroek, "Mr. Chico", which was the most important contributor and supporter of the company. This phase marked the entry of a new generation in the direction of the company, with administrative modernity and maintenance of the founders' ideals.

In 1999, the company took another decisive and transforming step in its history, through a joint venture with the German company Amazon Werke.

In 2000, the first precision farming project on a commercial level was created, named Aquarius, which today operates in agricultural machinery research tenable precision farming; it has one of the largest databases in the world.

In 2001, commercial alliance with the agricultural industrial Sfil Fortaleza Ltd., which operated in the planters and seeders regional market, the company's new brand was created.

In 2006, significant changes in the corporate base of the company gave the daughter of Franciscus, Susana and the grandchildren the control of the company, settling the entry of the third and fourth generation. The partnership with SfiI was undone and the old brand returned. Through negotiation with the shareholders in Germany, the sprays factory now has the stock control of the company. The industrial base was expanded, which significantly contributed to the growth of the products portfolio, strengthening the brand and enabling a greater participation in national and international markets.

In 2008, company made an entry in the planting market, making it the industry with the most complete line of agricultural machinery in Brazil.

In 2009, inspired by its evolution philosophy, the Stapelbroek Trennepohl family which owns $99.64 \%$ of the company's shares, made strategic investments which guaranteed greater market share and sustainable growth of the company. Another product was introduced to its line, the Gladiators self-propelled sprayers, which boast a technological package making it the only self-propelled sprayers in Brazil factory equipped with such a technology. The company also invested in its foundry, located in the town of Carazinho, Rio Grande do Sul State, and it supplies the cast metal used in the production of agricultural machinery.

In 2010, the company completed 50 years of age, with the pride of being a family-owned company with a management based on principles such as transparency, sharing of results, sustainable growth, confidence, and 
commitment. A company with professional and responsible management, based on planning and strategies maintains the strength of the brand, making it more present on the world stage.

In 2012, in order to value the employee and their partners and satisfy its customers, the company invested in new projects. Increasing manufacturing space and investing heavily in projects bring the employee closer to the company, resulting in work satisfaction and quality. The "Tiger Look" project comes to life, which aims to attract, find, and retain talent in the company. The Iris Project is also put into practice, which proposes a revision of existing processes in the search for company production excellence and total satisfaction of customers.

In 2013, in order to cover a region in which the metal-mechanic sector is promising, the company buys $80 \%$ of metallurgy in the town of Santa Rosa, Rio Grande do Sul State. A new 10,000 square meters plant is being built two miles away from the ring road.

\section{Results and Discussion}

Through this study, it is seen that the company is going through a period of adaptation to its new facilities, adapting the infrastructure in Não-Me-Toque to the new branch in Santa Rosa, Rio Grande do Sul State, a larger branch.

However, all adjustments are being made gradually, so that structural and staff adjustment is efficient.

According to A. Coelho and P. Coelho (2003), the ideal structure or the ideal structure levels for a company are issues of complex approach and of debatable relevance. The organizational structure presents a transitional and volatile character and the extension in which the volatility of the environment the company operates meets the requirements of this new format. Accordingly, the adaptability of the organizational structures may be a more relevant and current theme.

The structure of the company is divided, the direction includes all other sectors, but each has a leader or a boss, including quality management, quality control, and others sectors.

The engineering direction controls information technology, product engineering, plant, and tooling. The production direction controls all sectors related to the final product and also logistics. The production control planning controls the commercial area.

As the organizational chart covers many areas, internal communication is verbally passed on by the heads of each sector to the employees. The company's headquarters has 247 employees and the Não-me-Toque, Rio Grande do Sul State, has 2,690 employees.

The important factors revealed by the management, are the mission, vision, and values, which are key points of every company. These demonstrate that the company is concerned with both its staff and customers, according to the mission.

The company presents in its mission the concern to meet the global market with excellence in products and generate customer satisfaction, so that its employees feel proud to work in the company.

Vision is the look of the company's managers to a future of long or short term. The company's vision aims to "be a strong brand with international presence and leader in Latin America in the segments in which it operates and be recognized for the excellence of its products and services" by 2017.

The excellence in products and services is a constant concern for the company and is strongly marked in its management policy. The values, which are the company's driving force are unlikely to be changed and the company wants all employees to embody and transmit are: valuation of employees; respect for customers and 
suppliers; excellence in products and services; commitment and trust; pioneering; continuous innovation; simplicity; constant evolvement; and continuous and steady growth. This is the structure of thought that moves the company for the future.

However, the organization's quality policy is related to services, the company has the following quality policy: to produce products and provide services that meet the requirements; satisfy customers and employees; and provide profitability through continuous improvement and an efficient management system.

Regarding the efficiency of the management system processes, the company's manager links the efficiency in processes to advances in technology and the continuous evolution of mechanical metal industry, the responses obtained in the market and acceptability of products and services. The headquarter is taking the technology and structure to the Santa Rosa branch, providing new processes within the company, and adapting the organization to technological change.

In the strategy field, the company is not inert to the events of the external everyday life, which includes strategic planning and adapts to the current market format, as revealed by the plant manager, "the company is always looking at least three years into the future, being monitored and adapted when necessary".

Marketing is an important point regarding competitiveness. It's a very important tool and a very competitive environment. As the company is adapting to a new organizational structure, marketing has been taken care of by the headquarters.

The company believes that a motivated employee makes the company more profitable. So it tries to encourage the employees through motivational meetings and a bonus program for goals achieved. According to Tamayo and Paschoal (2003), the study of motivation at work gets considerable interest by the international literature, probably due to their close relationship with the individual and organizational productivity. The problem of work motivation lies inevitably in the context of the interaction of the organization's interests with the interests of the employee. Both parties involved in a partnership in which each one has explicitly and/or implicitly, their requirements, and demands.

Another important factor, in the view of managers, is innovation. As obsolete technology generates great amounts of environmental waste, it is estimated by the Brazilian Association for Public and Special Waste Disposal that companies generate about 69 million tons of waste per year.

The company treats environmental issues according to the law; the waste is sent to specialized companies that collect and treat it efficiently and appropriately.

It is noted that the company is adapting to a new structure and this transition has caused many internal changes. However, it has been adapting to new technologies, such as equipment, new manufacturing processes, and new machines. Thus, it becomes clear that the company seeks to keep improving and investing in new branches and staff, becoming an agent of action and innovation.

The company has the vision of a complex society, increasingly interactive and has gone to great lengths to turn the new Santa Rosa branch a great champion in the metalworking area. In 2013, the company was elected the best and largest companies in Brazil for the fourth time by the Exame Magazine. The expectations of the new plant are the best profitability and new business for the company to generate more jobs and income for the society in the region.

\section{Conclusions}

Organizational changes are essential in the current situation; they often break internal and external structural 
paradigms that would not be perceived by employees and company managers. However, such changes need to be very detailed and implemented through effort of each company member, focusing on continuous improvement which is a philosophy that preaches teamwork and the decisive participation of the people in solving organizational problems.

Regarding the company studied, the structural change has been going on continuously, it is perceived by the new environment that is changing and requires the participation of all involved.

At the moment, the company's challenge for managers is to train professionals with the same vision in all other branches, in an integrated manner, focusing on this new company structure and tuned to the stated objectives. However, the company is aware that structural changes cannot reate instability and undermine employee productivity, but has to be sure that the expectations of the leaders are achieved.

It is clear that the company has been going through a complex process; there is a concern about the future and the innovations that have occurred and the engagement and motivation of the staff in the long run.

Reflection on the results of this study encourages future researches related to business management, when it comes to adapting to these changes and even how the long-term productivity will be affected.

\section{References}

Al-Bahussin, S. A., \& El-Garaihy, W. H. (2013). The impact of human resource management practices, organizational culture, organizational innovation and knowledge management on organizational performance in large Saudi organizations: Structural equation modeling with conceptual framework. Journal of International Business Management, 8(22), 1-19.

Allen, N. J., \& Meier, J. P. (1991). A three-component conceptualization of organizational commitment. Human Resource Management Journal, 1, 61-89.

Borges, L. O., Lima, A. M. S., \& Vilela, E. C. (2004). Commitment to work and support in a culture and organizational context. Retrieved from http://dx.doi.org/10.1590/S1676-56482004000100011

Brito, R. P., \& Brito, L. A. L. (2012). Competitive advantage and its relation to performance: A value-based approach. Brazilian Administration Journal, 16(3), 60-75.

Coelho, A., \& Coelho, P. (2003). The structural weaknesses of organizations: The Iberian example. Journal of Contemporary Management, 7, 143-164.

Feurschutter, S. G. (1997). Organizational culture and power dependencies: Structural change in a computer branch of the organization. Journal Contemporary Administration, 1(2), 73-95.

Fleury, A. C. C., \& Fleury, M. T. L. (2003). Competitive strategies and core competencies: Perspectives for the internationalization of industry in Brazil. Journal of Production Management, 10(2), 129-144.

Jabbour, C., \& Santos, F. C. A. (2007). Development of sustainable products: The role of people management. Journal of Public Administration, 41(2), 283-307.

Keller, L., \& Kotler, P. (2009). Marketing management (12th ed.). Sao Paulo: Pearson Prentice Hall.

Rabechini, J. R., \& Carvalho, M. M. (2003). Profile of skills in project teams. Retrieved from http://www.scielo.br/scielo.php?script=sci_arttext\&pid=S1676-56482003000100013\&lng=pt\&nrm=iso

Sacomano, N. M., \& Escrivão, F. E. (2000). Organizational structure and work teams: A study of organizational changes in four major companies. Journal of Production Management, 7(2), 136-145.

Souza, E. M., \& Aguiar, A. C. (2011). Posthumous publications of Henri Fayol: Revisiting its administrative theory. Mackenzie Administration Journal, 12(1), 204-227.

Tamayo, A., \& Paschoal, T. (2003). The relationship of motivation to work with the employee's goals. Brazilian Administration Journal, 7(4), 33-54. 